\title{
Insufficient radiofrequency ablation promotes hepatocellular carcinoma cell progression via autophagy and the CD133 feedback loop
}

\author{
XIAOFEI WANG, QINGSONG DENG, KAI FENG, SHIHAN CHEN, \\ JIAYUN JIANG, FENG XIA, KUANSHENG MA and PING BIE \\ Department of Hepatobiliary Surgery, Southwest Hospital, \\ Third Military Medical University, Chongqing 400038, P.R. China
}

Received August 14, 2017; Accepted April 19, 2018

DOI: 10.3892/or.2018.6403

\begin{abstract}
Insufficient radiofrequency ablation (iRFA) often leads to residual hepatocellular carcinoma (HCC) progression. However, the mechanism is still poorly understood. In the present study, we demonstrated that LC3B protein expression levels were significantly increased in the residual hepatocellular carcinoma cells after radiofrequency ablation (RFA) treatment in vivo. Moreover, iRFA promoted autophagy, autophagosome formation and autophagic flux in Huh-7 and SMMC7721 cell lines in vitro. In addition, iRFA induced HCC cell viability and invasion. However, blockade of autophagy by the autophagosome inhibitor 3-methyladenine (3-MA) suppressed iRFA-induced cell viability and invasion. Furthermore, we revealed that the expression of liver cancer stem cell marker CD133 was also significantly increased in the residual hepatocellular carcinoma cells after RFA treatment in vivo, and was positively correlated with LC3B protein expression. iRFA also promoted CD133 protein expression in Huh-7 and SMMC7721 cell lines in vitro. CD133 was localized to autophagosomes, and was suppressed by 3-MA or chloroquine (CQ) after iRFA treatment. CD133 downregulation also suppressed iRFA-induced cell viability, invasion and autophagy. Collectively, our results indicated that RFA may promote residual HCC cell progression by autophagy and CD133 feedback loop.
\end{abstract}

\section{Introduction}

Hepatocellular carcinoma (HCC) is the fifth most common malignant tumor worldwide and is the third leading cause

Correspondence to: Professor Kuansheng Ma, Department of Hepatobiliary Surgery, Southwest Hospital, Third Military Medical University, Chongqing 400038, P.R. China

E-mail: makuansheng654@163.com

Key words: insufficient radiofrequency ablation, hepatocellular carcinoma, autophagy, CD133, LC3B of cancer-related mortality (1). For the treatment of HCC, a variety of modalities have been used, including moleculartargeted therapy, transarterial chemoembolization (TACE), liver transplantation and local tumor ablation [e.g., irreversible electroporation and radiofrequency ablation (RFA)] (2). Among these, RFA is accepted as a potentially curative local treatment for patients with early-stage HCC (3). However, tumor tissues experience insufficient radiofrequency ablation (iRFA) with temperatures $\left(60-42^{\circ} \mathrm{C}\right)$ too low to kill all of the cancer cells, resulting in rapid and aggressive recurrence of HCC after RFA (4-6). For instance, Yoshida et al (7) revealed that iRFA promoted HCC spread and growth by transiently inducing EMT-like changes and an enhanced malignant potential. Liu et al (8) reported that RFA increased VEGF expression via CaMKII-induced ERK activation, and then accelerated residual HCC growth. However, the mechanisms underlying the RFA-induced tumor promotion remain largely unexplored.

Autophagy is an evolutionarily conserved, intracellular self-protective mechanism for the degradation of cytoplasmic material, damaged organelles and aggregate-prone proteins in lysosomes $(9,10)$. Recently, considerable evidence has supported that autophagy plays a critical role in many human diseases, including cancer. In pancreatic cancer, the inhibition of autophagy suppressed cell growth in vitro and tumor progression in vivo (11). In HCC, LC3-II (a key autophagic marker) expression levels were positively related with the development and a poor prognosis of HCC (12). Chang et al (13) revealed that inhibition of autophagy reduced viability of HCC. Moreover, autophagy can act as an accomplice of survival, malignant progression and distant metastasis of HCC cells under adverse conditions (11). Peng et al (14) demonstrated that hypoxia-induced autophagy resulted in resistance of HCC cells to chemotherapeutic agents. In the present study, our results indicated that $\mathrm{LC} 3 \mathrm{~B}$ expression was upregulated in the residual hepatocellular carcinoma cells after RFA treatment in vivo. However, the role of autophagy in rapid and aggressive recurrence of HCC after RFA remains largely unknown. Thus, we sought to determine the potential role and mechanism of autophagy in rapid and aggressive recurrence of HCC after RFA. Our results demonstrated that autophagy and the CD133 
feedback loop are indispensable for iRFA-induced tumor cell progression in $\mathrm{HCC}$.

\section{Materials and methods}

Ethics statement. In the present study, the use of human tissue samples and all experimental procedures and protocols were approved by the Ethics Committee of the First Affiliated Hospital of Third Military Medical University with the following reference no. 2013(47).

Patients and samples. Hepatocellular carcinoma (HCC) tissues were obtained from 31 patients who underwent surgical resection between December 2013 and December 2015 at the Southwest Hospital, Third Military Medical University. Sixteen specimens were obtained from HCC patients with radiofrequency ablation (RFA) treatment at our hospital, and the remaining 15 specimens were obtained from HCC patients with non-RFA treatment. RFA treatment was performed with the patient under endotracheal general anesthesia. Then, patients were submitted to RFA with ultrasonography guidance, utilizing a generator providing $460 \mathrm{kHz}$ alternating current and a semi-flax retractable multi-pronged curved electrode-needle (RITA Medical Systems, Inc., Mountain View, CA, USA). The average target temperature was set at $100-110^{\circ} \mathrm{C}$, and ablation was continued for 25 min depending on the desired ablation size. The process was monitored by real-time ultrasound to ensure 1-cm margins.

Immunohistochemical analysis. Human HCC tissues were fixed in $4 \%$ paraformaldehyde overnight, and subsequently embedded in paraffin. The paraffin-embedded tissues were cut into standard $6 \mu \mathrm{m}$ sections, deparaffinated in xylene and rehydrated through graded alcohol solutions. Antigen retrieval was performed $10 \mathrm{~min}$ at $92^{\circ} \mathrm{C}$ in EDTA $(10 \mathrm{mmol} / 1$, $\mathrm{pH}$ 8.0) in a water bath. Endogenous peroxidases were inactivated by immersing the sections in $0.3 \%$ hydrogen peroxide $\left(\mathrm{H}_{2} \mathrm{O}_{2}\right)$ for $12 \mathrm{~min}$. Next, the sections were blocked with $5 \%$ goat serum for $60 \mathrm{~min}$ at $37^{\circ} \mathrm{C}$. The slides were incubated with rabbit polyclonal antibody against human LC3B (1:1,000; cat. no. ab63817; Abcam, Cambridge, MA, USA) and mouse monoclonal antibody against human CD133 (1:50; cat. no. MAB4399-I; EMD Millipore, Billerica, MA, USA) overnight at $4^{\circ} \mathrm{C}$. Next, the slides were treated with the appropriate HRP-conjugated goat antibody against rabbit/mouse (1:1,500; cat. no. KIT-5920; Maixin Biotechnology, Co., Ltd., Fuzhou, China) for $45 \mathrm{~min}$ at $37^{\circ} \mathrm{C}$, and then developed with 3,3'-diaminobenzidine. Finally, the slides were counterstained with hematoxylin and mounted. The slides were examined under an Olympus light microscope (Leeds Precision Instruments, Minneapolis, MN, USA). LC3B and CD133 protein expression in tissues were determined according to methods described by Pinheiro et al (15). Sections were semi-quantitatively scored for the extent of immunoreactions as follows: 0, 0\% immunoreactive cells; $1,<5 \%$ immunoreactive cells; 2, 5-50\% immunoreactive cells; and 3, >50\% immunoreactive cells. Additionally, the staining intensity was semi-quantitatively scored as 0 (negative), 1 (weak), 2 (intermediate), or 3 (strong). The final immunoreaction score was defined as the sum of both parameters.
Cell lines and cell culture. Huh-7 and SMMC7721 cells were obtained from the Cell Bank Type Culture Collection of the Chinese Academy of Sciences (Shanghai, China). Huh-7 cells were cultured in Dulbecco's modified Eagle's medium (DMEM; Invitrogen; Thermo Fisher Scientific, Inc., Waltham, MA, USA) containing 10\% fetal bovine serum (FBS; Gibco; Thermo Fisher Scientific, Scoresby VIC, Australia) and 1\% penicillin-streptomycin (Gibco; Thermo Fisher Scientific) at $37^{\circ} \mathrm{C}$ in a humidified atmosphere of $5 \% \mathrm{CO}_{2} . \mathrm{SMMC} 7721$ cells were cultured in RPMI-1640 medium (Invitrogen; Thermo Fisher Scientific) containing 10\% FBS (Gibco; Thermo Fisher Scientific).

Heat treatment. iRFA treatment was performed in vitro as previously described (7). Huh-7 and SMMC7721 cells were seeded onto 6 -well plates $\left(5 \times 10^{4}\right.$ cells/well) and further incubated for $24 \mathrm{~h}$. Next, the plates were sealed and submerged in a water bath at a temperature setting of $50^{\circ} \mathrm{C}$ for $10 \mathrm{~min}$. Thereafter, the cells were maintained at $37^{\circ} \mathrm{C}$ for 12,24 and $48 \mathrm{~h}$. The cells that survived the treatment were used in subsequent experiments.

Autophagy inhibitors and knockdown of CD133. 3-Methyladenine (3-MA) and chloroquine (CQ) were purchased from Sigma-Aldrich (Merck KGaA, Darmstadt, Germany) and used to inhibit autophagy in Huh-7 and SMMC7721 cells. Huh-7 and SMMC7721 cells after heat treatment were incubated at $37^{\circ} \mathrm{C}$ for 12,24 or $48 \mathrm{~h}$ in the absence or presence of 3-MA (5 mM) or CQ (5 $\mu \mathrm{M})(16)$. Then, the cells were used for western blotting, transmission electron microscopy, confocal microscopy, CCK-8 and cell invasion assay.

The CD133 siRNA (CD133 KD) and negative control siRNA (con) were obtained from Shanghai GeneChem Co., Ltd. (Shanghai,China). The sequences used for the experiments were as follows: CD133 KD: 5'-CCUUUGUCUUUGGUGCAAA-3' con: 5'-UUCUCCGAACGUGUCACGU-3'.

Huh-7 and SMMC7721 cells were transfected using Lipofectamine 2000 (Invitrogen; Thermo Fisher Scientific) in 96-well or 6-well plates and then were further incubated for 24 or $48 \mathrm{~h}$, according to the manufacturer's instructions.

Western blotting. Tissues and cells were lysed in RIPA protein lysis buffer (Thermo Fisher Scientific, Rockford, IL, USA) containing protease inhibitors. The protein concentration was determined using a BCA protein assay (Beyotime Institute of Biotechnology, Jiangsu, China). Next, the proteins were denatured and separated via SDS-PAGE gel (15\% for separating LC3B and 6\% for separating CD133) and then transferred to nitrocellulose transfer membranes (Whatman, Piscataway, NJ, USA). The membranes were blocked with $5 \%$ non-fat powdered milk in phosphate-buffered saline (PBS) for $1 \mathrm{~h}$ at room temperature and then incubated with rabbit polyclonal antibody against human LC3B (1:800; cat. no. L7543; SigmaAldrich; Merck KGaA), mouse monoclonal antibody against human CD133 (1:500; cat. no. MAB4399-I; EMD Millipore), or rabbit polyclonal antibody against human GAPDH (1:200; cat. no. sc-25778; Santa Cruz Biotechnology, Dallas, TX, USA) overnight at $4^{\circ} \mathrm{C}$. The membranes were then washed extensively with TBST and incubated with goat antibody against mouse (1:10,000; cat. no. ab97040; Abcam) and goat antibody 
against rabbit (1:1,000; cat. no. ab7085; Abcam) for $1 \mathrm{~h}$ at room temperature. The signal was detected using an enhanced chemiluminescence system (Thermo Fisher Scientific) in accordance with the manufacturer's protocol. The results were normalized to GAPDH and expressed as relative densities.

Transmission electron microscopy. Huh-7 and SMMC7721 cells were exposed to iRFA treatment alone or iRFA treatment with 3-MA and then further incubated for $24 \mathrm{~h}$. Next, the cells were fixed with $2.5 \%$ glutaraldehyde and then rinsed three times (30 min each) with 0.1 M PBS. Subsequently, the cells were fixed with $1 \%$ osmium tetroxide for $2 \mathrm{~h}$ and gradientdehydrated in acetone, saturated, and embedded in epoxy 618. Semi-thin slices and then ultra-thin slices were prepared and stained with uranium and lead. Finally, autophagy was evaluated using transmission electron microscopy (Tecnai 10; Philips, Eindhoven, The Netherlands).

Confocal microscopy. Huh-7 and SMMC7721 cells were exposed to iRFA treatment in the presence of 3-MA or CD133-siRNA and then further incubated for $24 \mathrm{~h}$. After treatment, the cells were washed with PBS, incubated for $10 \mathrm{~min}$ at $37^{\circ} \mathrm{C}$ in $4 \%$ paraformaldehyde and then permeabilized with $0.1 \%$ Triton $\mathrm{X}-100$. Next, the cells were incubated for $1 \mathrm{~h}$ with a primary antibody at $37^{\circ} \mathrm{C}$, washed extensively with $\mathrm{PBS}$ buffer, and then incubated for $1 \mathrm{~h}$ with a secondary antibody. The primary antibodies used were mouse monoclonal antibody against human CD133 (1:50; cat. no. MAB4399-I; EMD Millipore) and rabbit polyclonal antibody against human LC3B (1:200; cat. no. L7543; Sigma-Aldrich; Merck KGaA) and the secondary antibodies were Alexa Fluor 488-conjugated goat anti-rabbit (1:500; cat. no. A-11034; Thermo Fisher Scientific) and Alexa Fluor 568-conjugated goat anti-mouse (1:400; cat. no. A-21134; Thermo Fisher Scientific). After staining, coverslips were mounted with Vectashield (cat. no. H1200; Vector Laboratories, Burlingame, CA, USA) and analyzed by Radiance 2000 laser scanning confocal microscope (Carl Zeiss Microimaging, Thornwood, NY, USA). The number of autophagosomes using confocal microscopy were counted according to the methods described by Kader et al (17). The LC3B puncta were identified as highly fluorescent green aggregates. The number of LC3B puncta was quantified using the NIH ImageJ 1.41 software (National Institutes of Health, Bethesda, MD, USA) and 45 cells/group from 3 independent experiments were analyzed.

Cell Counting Kit-8(CCK-8) assay. Cell viability was detected by CCK-8 assay (Beyotime Institute of Biotechnology) according to the manufacturer's instructions. Huh-7 and SMMC7721 cells were exposed to iRFA treatment in the presence of 3-MA or CD133-siRNA and then further incubated for $24 \mathrm{~h}$. After treatment, the cells were cultured in 96-well plates $\left(3 \times 10^{3}\right.$ cells/well) and further incubated for 12, 24, 36 and $48 \mathrm{~h}$. The CCK-8 solution was added to each well. Next, the absorbance at $450 \mathrm{~nm}$ was measured with a microplate reader (Thermo Fisher Scientific). All the assays were performed in triplicate.

Cell invasion assay. Huh-7 and SMMC7721 cells were exposed to iRFA treatment in the presence of 3-MA or CD133-siRNA and then further incubated for $24 \mathrm{~h}$. Next, Transwell chambers (Costar; Corning Inc., Corning, NY, USA) were coated with $50 \mu \mathrm{g}$ reconstituted basement membrane matrix (BD Biosciences, San Jose, CA, USA). Then, $2 \times 10^{4}$ cells in $100 \mu 1$ serum-free medium were seeded into the upper chambers. A total of $600 \mu \mathrm{l}$ of DMEM containing $10 \%$ FBS was added to the lower chamber. After $48 \mathrm{~h}$ of incubation, the cells on the lower surface of the membrane were stained with crystal violet for $30 \mathrm{~min}$ and washed with PBS. The cells were counted in six random fields under a light microscope at an x200 magnification.

Statistical analysis. The data were analyzed using SPSS 18.0 statistical software (SPSS, Inc., Chicago, IL, USA) and presented as the means \pm SD from at least 3 independent experiments. The differences between groups in the western blot analysis, cell viability and cell invasion assays were analyzed using either the Student's t-test or the one-way ANOVA. The association between LC3B and CD133 in HCC tissues was calculated using the Spearman's correlation coefficient. $\mathrm{P}<0.05$ was considered to indicate a statistically significant result.

\section{Results}

RFA promotes $L C 3 B$ protein expression levels in human HCC tissues. To determine the effect of RFA on autophagy in human HCC tissues, we analyzed the LC3B protein expression levels in 16 HCC specimens with RFA treatment and 15 HCC specimens with non-RFA treatment by immunohistochemical analysis and western blotting. Immunohistochemical analysis results indicated that the expression of the LC3B protein was increased by $77.0 \%$ in HCC specimens with RFA treatment compared with that of HCC specimens with non-RFA treatment (Fig. 1A). As shown in Fig. 1B, western blotting results demonstrated that the expression of the LC3B protein was increased by 1.67-fold in HCC specimens with RFA treatment compared with that of HCC specimens with non-RFA treatment. These data provided us with experimental evidence that RFA induced LC3B protein expression levels in the human HCC tissues.

iRFA induces autophagy in HCC cells in vitro. To further address whether autophagy could be induced in HCC cells during iRFA, we investigated the LC3B-II protein expression in vitro, which is considered an accurate indicator of autophagy (18). Western blot analysis demonstrated that the ratio of LC3B-II to GAPDH in Huh-7 cells with iRFA treatment was increased by 2.67-fold after $12 \mathrm{~h}, 12.16$-fold after $24 \mathrm{~h}$ and 10.33-fold after $48 \mathrm{~h}$, respectively. In the other group, the expression of LC3B-II in SMMC7721 cells with iRFA treatment was upregulated by 2.8 -fold after $12 \mathrm{~h}, 8.51$-fold after $24 \mathrm{~h}$ and 5.72-fold after $48 \mathrm{~h}$, respectively. In addition, p62 (SQSTM1, an autophagy-specific substrate) protein expression levels in Huh-7 cells with iRFA treatment was decreased by $\sim 43.4 \%$ after $12 \mathrm{~h}, 76.2 \%$ after $24 \mathrm{~h}$ and $78.3 \%$ after $48 \mathrm{~h}$, respectively. Moreover, the expression of p62 in SMMC7721 cells with iRFA treatment was reduced by $\sim 78.3 \%$ after $12 \mathrm{~h}$, $87.0 \%$ after $24 \mathrm{~h}$ and $93.0 \%$ after $48 \mathrm{~h}$, respectively (Fig. 2A).

To further evaluate the effect of iRFA on autophagic flux, the autophagy inhibitors 3-MA and CQ were used. Our results 
A

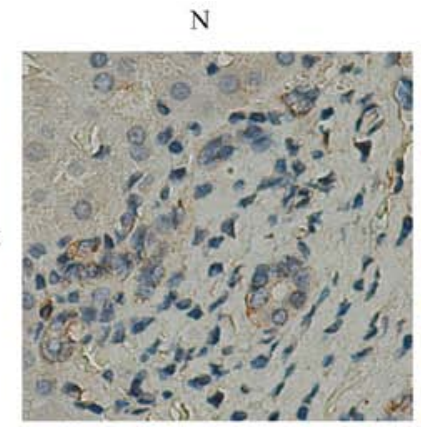

B

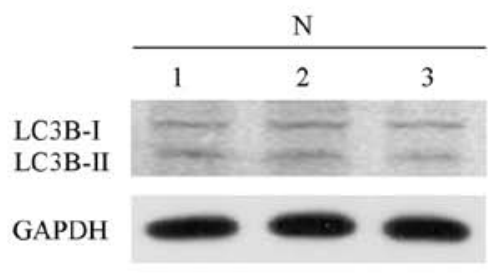

iRFA
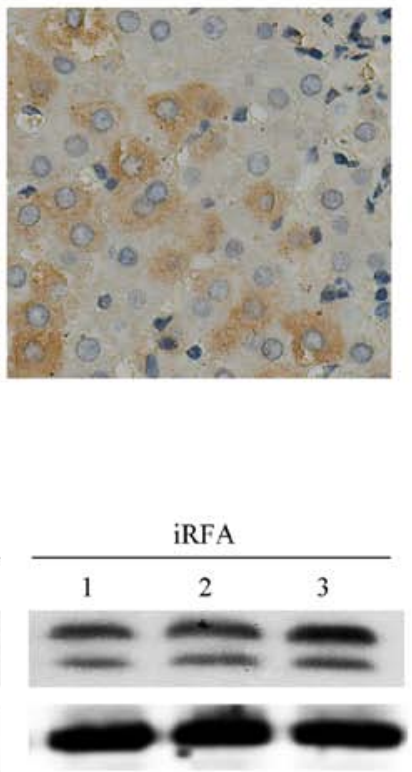
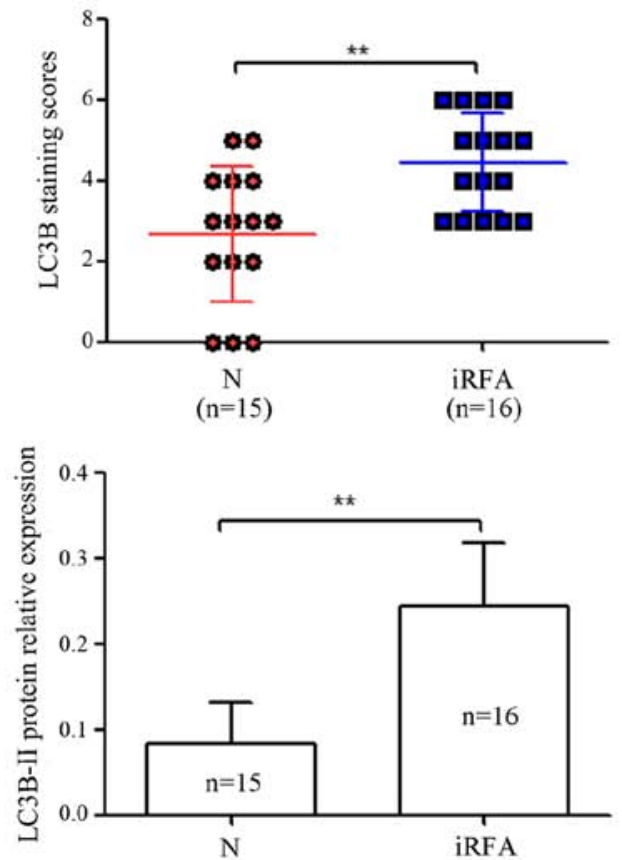

Figure 1. RFA induces LC3B protein expression in the residual HCC cells in vivo. LC3B protein expression was determined in 16 HCC specimens with RFA treatment and 15 HCC specimens with non-RFA treatment by $(\mathrm{A})$ immunohistochemical analysis and $(\mathrm{B})$ western blotting. ${ }^{* *} \mathrm{P}<0.01$.

demonstrated that 3-MA attenuated the levels of LC3B-II protein and significantly increased the accumulation of p62 protein (Fig. 2B), which is consistent with its ability to block autophagosome formation (19). Conversely, CQ, which blocks the maturation of autophagosomes and digestion of autophagic substrates (20), resulted in significant accumulation of LC3B-II and p62 protein in Huh-7 and SMMC7721 cells after iRFA treatment (Fig. 2B).

To further confirm that iRFA induces autophagy in Huh-7 and SMMC7721 cells, we analyzed autophagy by confocal microscopy and transmission electron microscopy (TEM). As shown in Fig. 2C, the formation of LC3B puncta in Huh-7 and SMMC7721 cells after iRFA treatment was increased by 7.50 -fold and 11.50-fold when compared with the control group, respectively (Fig. 2C). TEM results of Huh-7 and SMMC7721 cells after iRFA treatment also revealed an increase in the number of autophagosomes (Fig. 2D). In addition, 3-MA treatment reversed the effect of iRFA on the number of autophagosomes in Huh-7 and SMMC7721 cells (Fig. 2C and D).

Inhibition of autophagy suppresses the enhanced cell viability and invasion of HCC cells after iRFA treatment. To determine the effect of iRFA on HCC progression, the viabilities and invasion abilities of Huh-7 and SMMC7721 cells were assessed by CCK-8 and Transwell assays, respectively. The results of CCK- 8 assay indicated that the cell viability of iRFA-treated Huh-7 and SMMC7721 cells was increased by 32.1 and $33.8 \%$, respectively, when compared with the control group (Fig. 3A, $\mathrm{P}<0.01)$. Similarly, the invasive potential of iRFA-treated Huh-7 and SMMC7721 cells was increased by 0.97- and 1.15-fold, respectively, when compared with the control group (Fig. 3B, P<0.01). Next, to determine whether iRFA-induced autophagy played an important role in enhanced cell viability and invasion of HCC cells, autophagy was inhibited by 3-MA treatment. The results revealed that the cell viability of Huh-7 and SMMC7721 cells exposed to iRFA treatment with 3-MA was decreased by 21.0 and $19.6 \%$ when compared with the viability of cells exposed to iRFA treatment alone, respectively (Fig. 3A). Moreover, the invasive potential of Huh-7 and SMMC7721 cells exposed to iRFA treatment with 3-MA was suppressed by 47.1 and $40.1 \%$ when compared with the invasive potential of cells exposed to iRFA treatment alone, respectively (Fig. 3B).

CD133 is upregulated after iRFA treatment. Previous studies have demonstrated that tumor initiation and maintenance and high metastatic potential in several cancers have been linked to cancer stem cells (CSCs) (21). In pancreatic cancer, blockade of autophagy by pharmacological or genetic inhibitors reduced CSC populations, sphere-forming ability, drug resistance and tumor formation (22). However, the relationship between autophagy and CSCs in rapid and aggressive recurrence of HCC after RFA remains to be explored. To determine whether CD133 could be induced in HCC cells during iRFA, we investigated CD133 protein expression in vivo, which has recently been identified as a critical CSC marker (23). Immunohistochemical analysis results indicated that CD133 protein expression was increased by 1.06-fold in HCC specimens with RFA treatment compared with that of HCC specimens with non-RFA treatment $(\mathrm{P}<0.01$; Fig. 4A). In line with the previous data, western blot analysis demonstrated that CD133 protein expression was increased by 1.10 -fold and was positively correlated with LC3B protein expression in HCC specimens ( $r=0.636, \mathrm{P}<0.01$; Fig. 4B). Next, CD133 protein levels were determined in Huh-7 and SMMC7721 
A

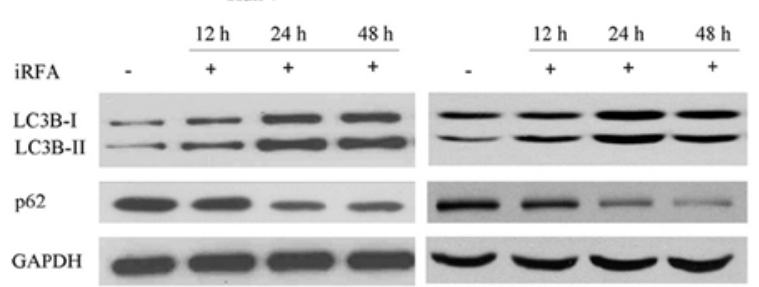

Huh-7

(x) SMMC772
Huh-7

网 SMMC7721
B

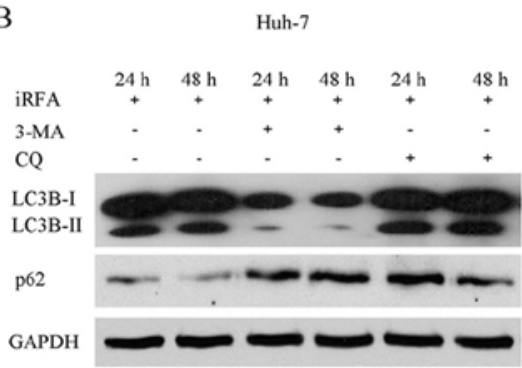

SMMC7721

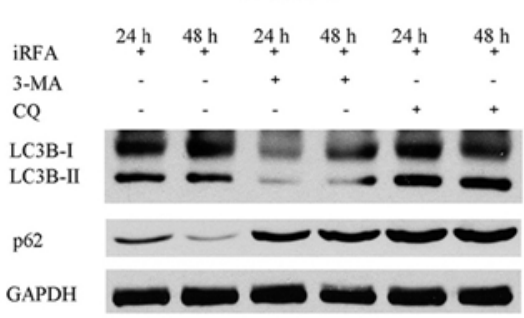

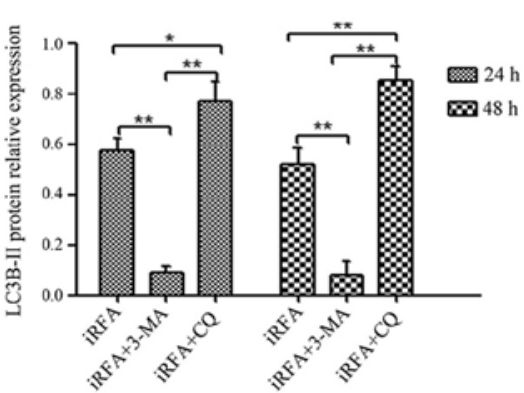

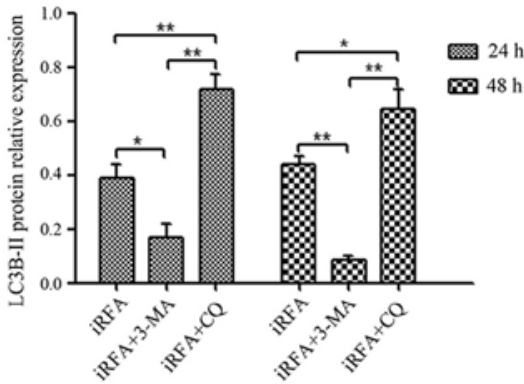

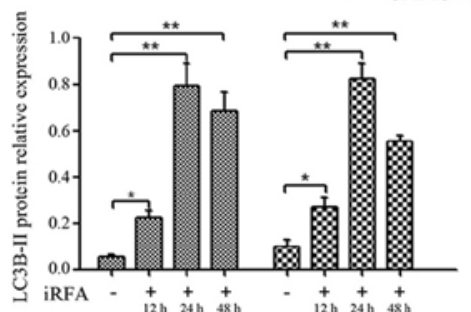

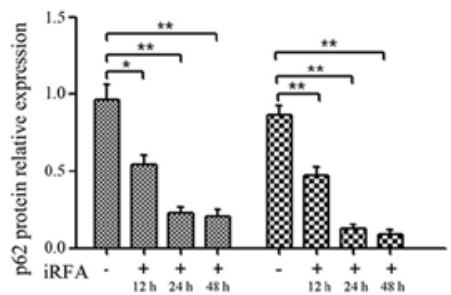

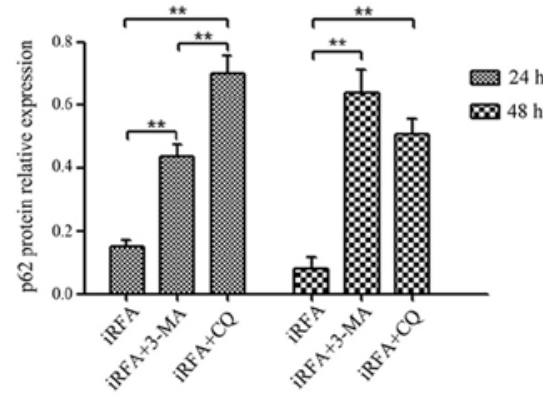

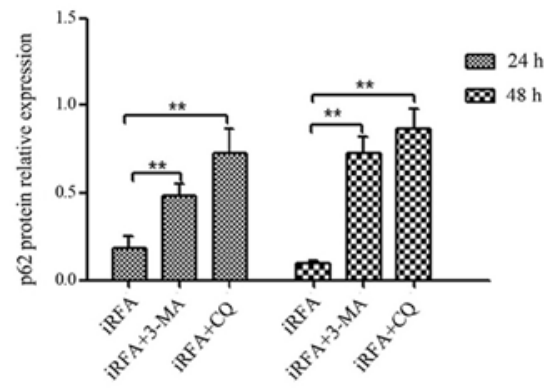

C

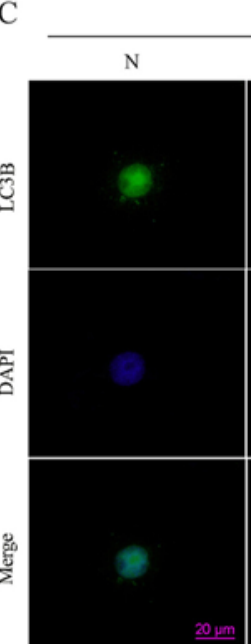

Huh-7
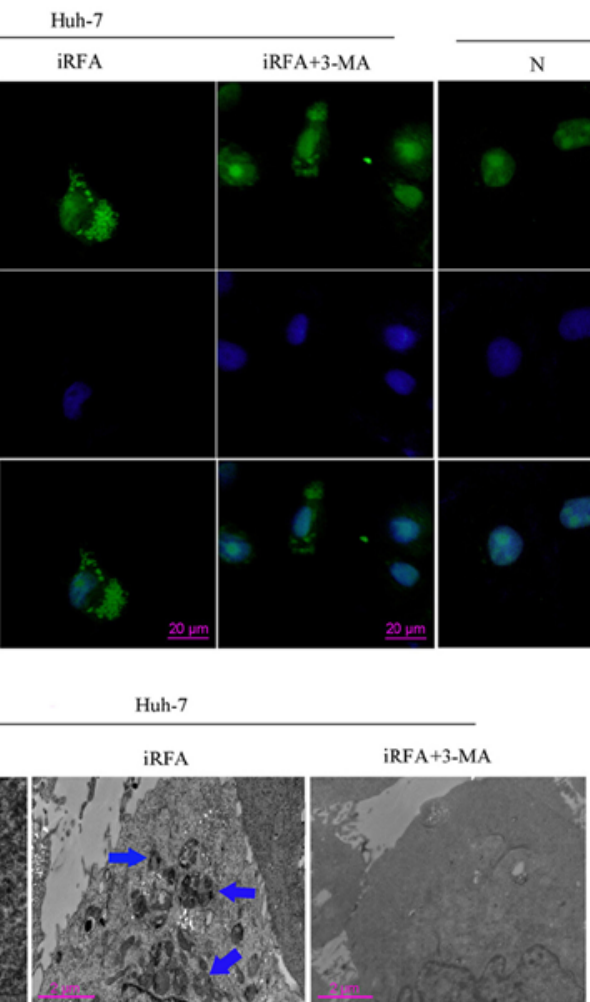

SMMC7721
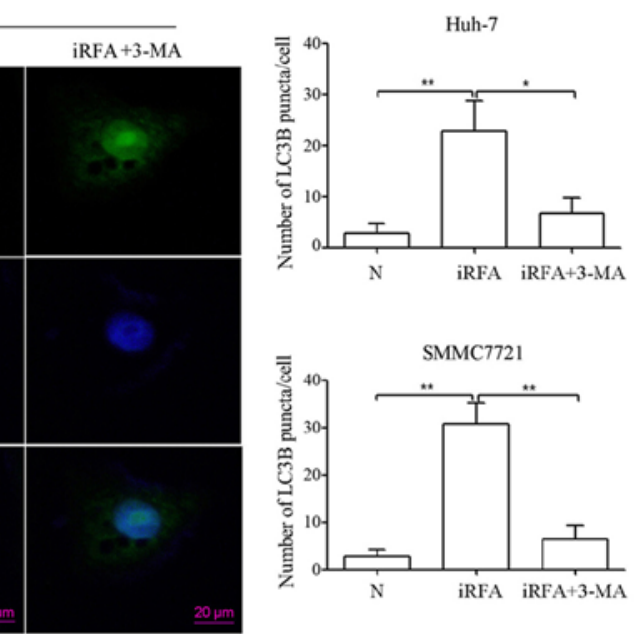

D

Huh-7
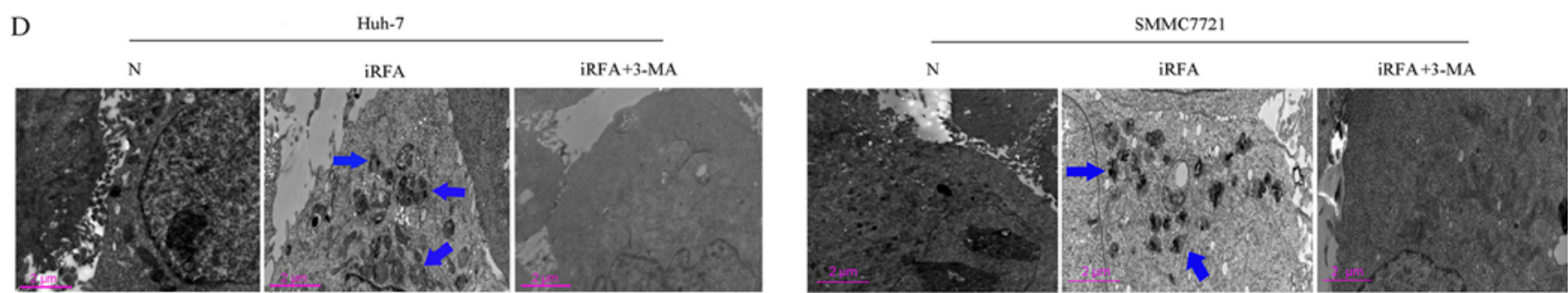

Figure 2. Autophagy is induced after iRFA treatment in vitro. (A) Huh-7 and SMMC7721 cells were exposed to iRFA treatment for 10 min, and cultured at $37^{\circ} \mathrm{C}$ for 12,24 and $48 \mathrm{~h}$. Then, LC3B and p62 protein expression was determined by western blotting. (B) Huh-7 and SMMC7721 cells were exposed to iRFA treatment in the absence or presence of 3-MA $(5 \mathrm{mM})$ or CQ $(5 \mu \mathrm{M})$, and cultured at $37^{\circ} \mathrm{C}$ for 24 and $48 \mathrm{~h}$. Autophagic flux was measured by western blotting. (C and D) Huh-7 and SMMC7721 cells were exposed to iRFA treatment in the absence or presence of 3-MA (5 mM), and cultured at $37^{\circ} \mathrm{C}$ for 24 h. Autophagosome formation was visualized by confocal microscopy and transmission electron microscopy. ${ }^{*} \mathrm{P}<0.05 ;{ }^{* * *} \mathrm{P}<0.01$. 
A

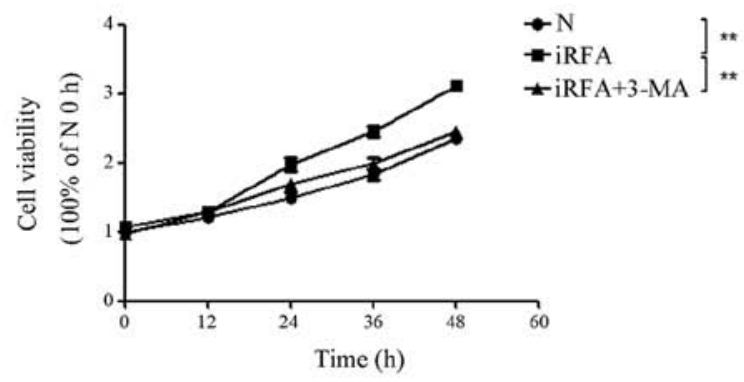

B

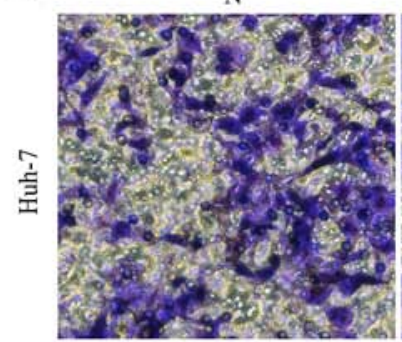

N

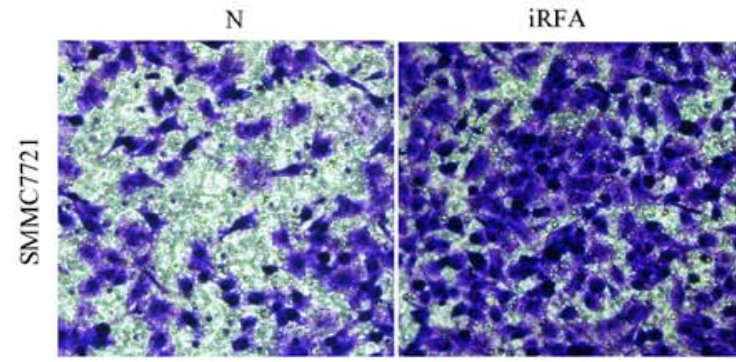

iRFA

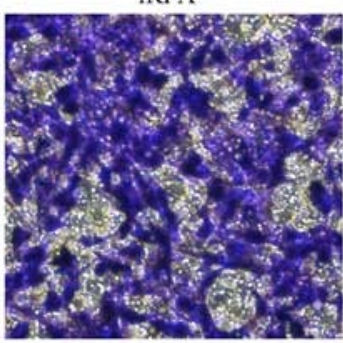

iRFA

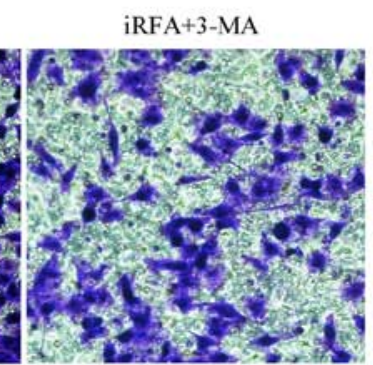

iRFA+3-MA

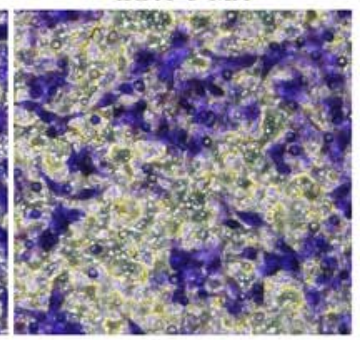

SMMC7721
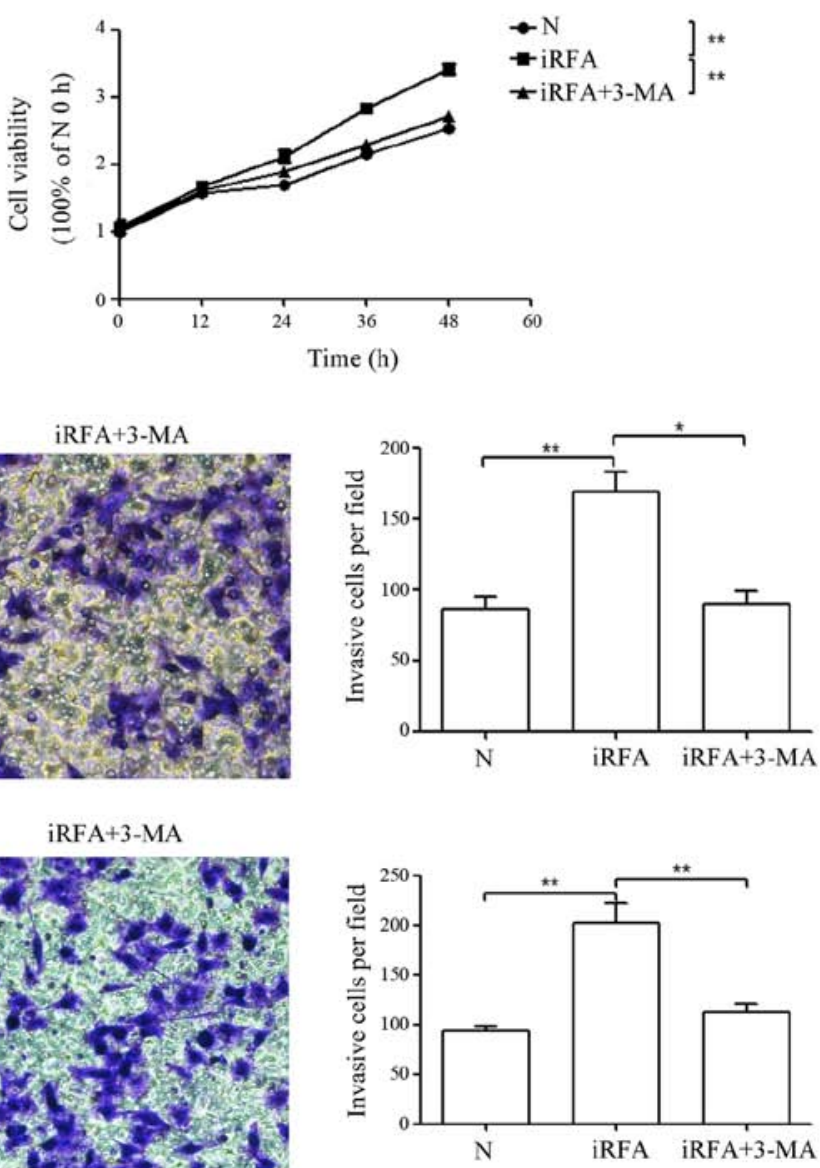

Figure 3. Blocking of autophagy partially reverses the effect of iRFA treatment on HCC cell viability and invasion. (A) Cell viability analysis of Huh-7 and SMMC7721 cells with iRFA treatment in the absence or presence of 3-MA (5 mM). (B) Huh-7 and SMMC7721 cells were exposed to iRFA treatment in the absence or presence of 3 -MA $(5 \mathrm{mM})$, and cultured at $37^{\circ} \mathrm{C}$ for $48 \mathrm{~h}$. Then, cell invasion was detected. Data are presented as the mean $\pm \mathrm{SD}(\mathrm{n}=3)$. ${ }^{*} \mathrm{P}<0.05$; ${ }^{* *} \mathrm{P}<0.01$.

cells after iRFA treatment for 12,24 and $48 \mathrm{~h}$ at $50^{\circ} \mathrm{C}$. Our results demonstrated that $\mathrm{CD} 133$ protein expression in Huh-7 cells with iRFA treatment was increased by 1.79 -fold after 12 h, 4.43-fold after $24 \mathrm{~h}$ and 3.57-fold after $48 \mathrm{~h}$, respectively. In the other group, CD133 protein expression in SMMC7721 cells exposed to iRFA treatment was upregulated by 1.67 fold after $12 \mathrm{~h}, 5.94$-fold after $24 \mathrm{~h}$ and 4.06 -fold after $48 \mathrm{~h}$, respectively (Fig. 4C). Furthermore, confocal microscopy results indicated that the $\mathrm{CD} 133$ protein colocalized with the autophagy protein LC3B in Huh-7 and SMMC7721 cells after iRFA treatment (Fig. 4D). These results demonstrated that CD133 played an important role in rapid and aggressive recurrence of HCC after RFA.

Inhibition of autophagy suppresses CD133 expression of HCC cells after iRFA treatment. To determine whether iRFAinduced autophagy played an important role in regulating the expression of the CD133 protein, autophagy was inhibited by 3-MA or CQ treatment. Western blotting results demonstrated that the expression of the CD133 protein in Huh-7 cells exposed to iRFA treatment with 3-MA or CQ) was suppressed by $61.4 \%$ after $24 \mathrm{~h}$ and $60.2 \%$ after $48 \mathrm{~h}$, respectively, when compared with that of cells exposed to iRFA treatment alone (Fig. 5A, $\mathrm{P}<0.05)$. In addition, the decrease in CD133 protein expression of Huh-7 cells exposed to iRFA treatment with CQ exceeded $63 \%$ when compared with that of cells exposed to iRFA treatment alone (Fig. 5A, P<0.05). A similar effect occurred in SMMC7721 cells, wherein there was a significant decrease in the CD133 protein expression (Fig. 5A). Furthermore, confocal microscopy results indicated that both the CD133 protein and the autophagy protein LC3B in iRFA-treated Huh-7 and SMMC7721 cells after inhibition of autophagy (3-MA) was significantly decreased (Fig. 5B).

CD133 knockdown suppresses the enhanced cell viability and invasion of HCC cells after iRFA treatment. To assess whether iRFA-induced CD133 played an important role in enhanced cell viability and invasion of HCC cells, we transfected the iRFA-treated Huh-7 and SMMC7721 cells with CD133-siRNA or negative control siRNA. As shown in Fig. 6A, CD133 protein expression in iRFA-treated Huh-7 and SMMC7721 cells transfected with CD133-siRNA was downregulated by 73.5 and $88.9 \%$ when compared with that in cells transfected with the negative control siRNA, respectively (Fig. 6A). Moreover, cell viability in iRFA-treated Huh-7 and SMMC7721 cells after CD133 knockdown was suppressed by 35.6 and $38.0 \%$ when compared with that in cells transfected with the negative control siRNA, respectively (Fig. 6B). Similarly, the invasion 
A
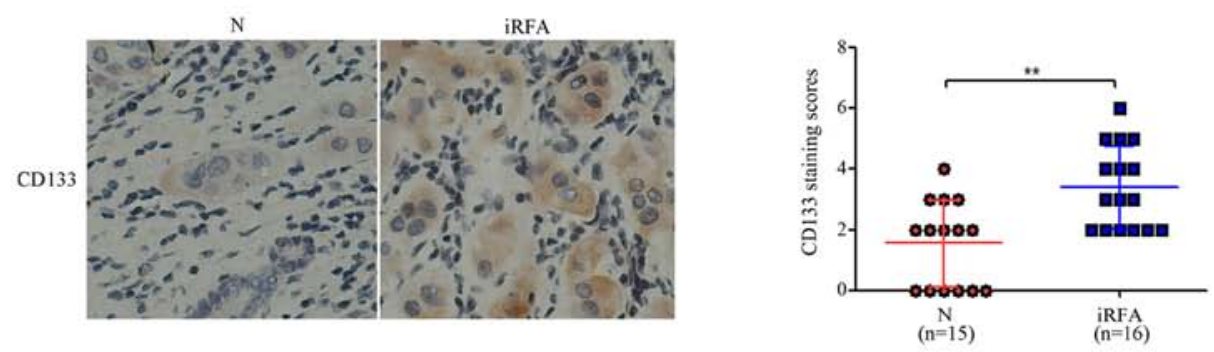

B
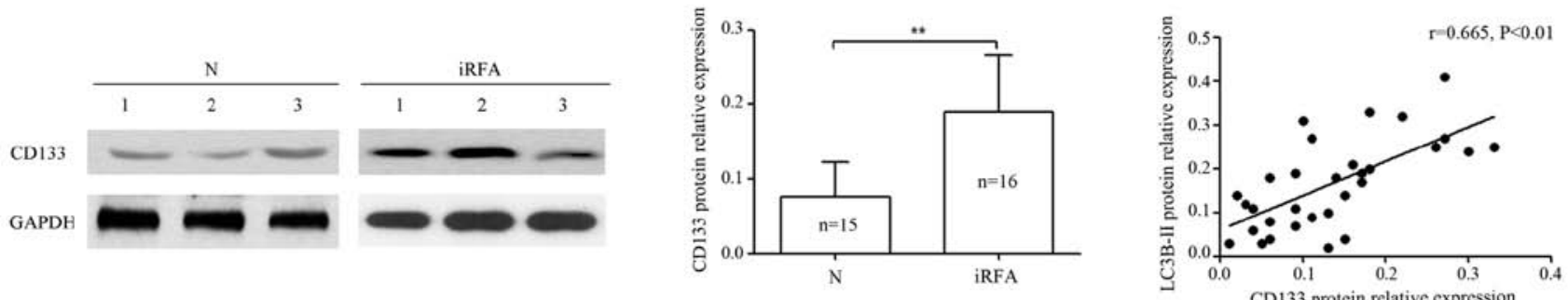

C
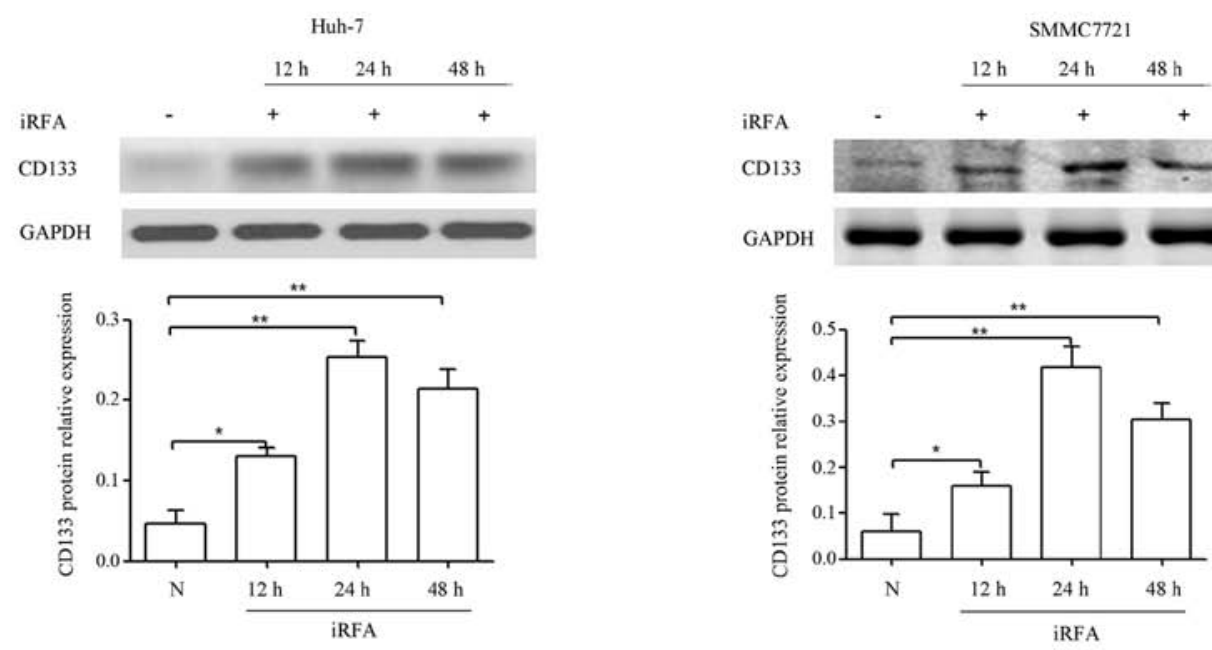

D

Huh-7

LC3B

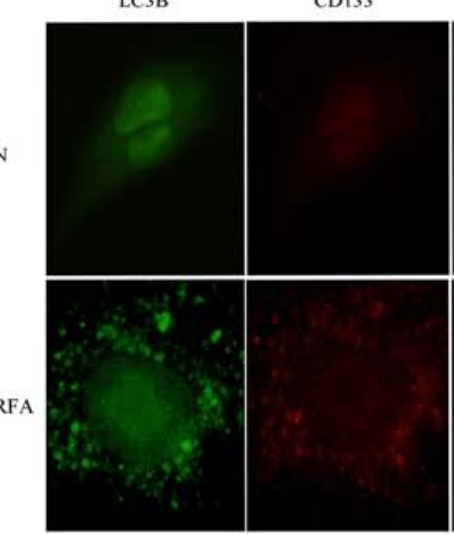

DAPI

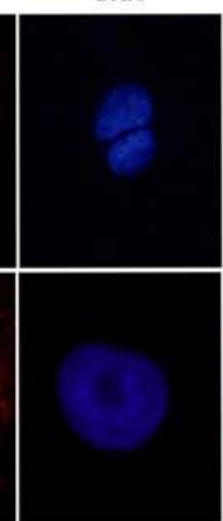

Merge

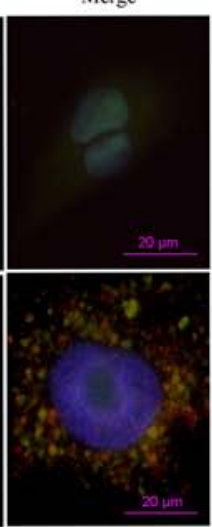

SMMC7721

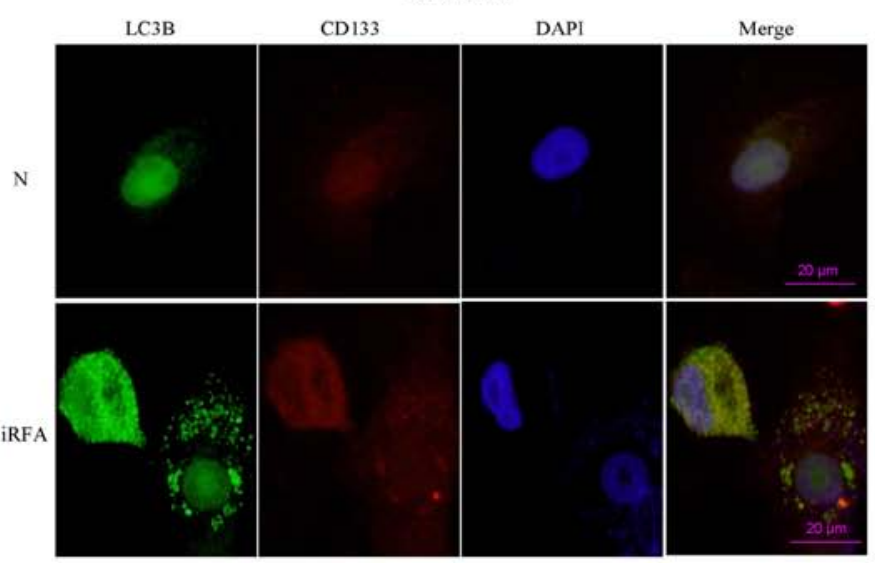

Figure 4. CD133 protein is upregulated and positively correlated with the LC3B-II protein in vivo. (A) CD133 protein expression was determined in 16 HCC specimens with RFA treatment and 15 HCC specimens with non-RFA treatment by immunohistochemical analysis. (B) CD133 protein expression was determined in $16 \mathrm{HCC}$ specimens with RFA treatment and $15 \mathrm{HCC}$ specimens with non-RFA treatment by western blotting. GAPDH was used as a loading control. The Spearman's correlation analysis clearly demonstrated positive correlation between CD133 and LC3B-II protein expression $(r=0.636, P<0.01)$. (C) Huh-7 and SMMC7721 cells were exposed to iRFA treatment for $10 \mathrm{~min}$, and cultured at $37^{\circ} \mathrm{C}$ for 12,24 and $48 \mathrm{~h}$. Then, CD133 protein expression was determined by western blotting. GAPDH was used as a loading control. (D) Huh-7 and SMMC7721 cells were exposed to iRFA treatment for 10 min, then cultured at $37^{\circ} \mathrm{C}$ for $24 \mathrm{~h}$, and subjected to confocal microscopic analysis. ${ }^{*} \mathrm{P}<0.05 ;{ }^{* *} \mathrm{P}<0.01$.

abilities determined using Transwell assay in iRFA-treated Huh-7 and SMMC7721 cells after CD133 knockdown were suppressed by 53.2 and $51.9 \%$, respectively (Fig. 6C).
CD133 knockdown suppresses autophagy of HCC cells after iRFA treatment. In HCC, CD133 is involved in cell survival through regulation of autophagy and glucose uptake (24). To 
A
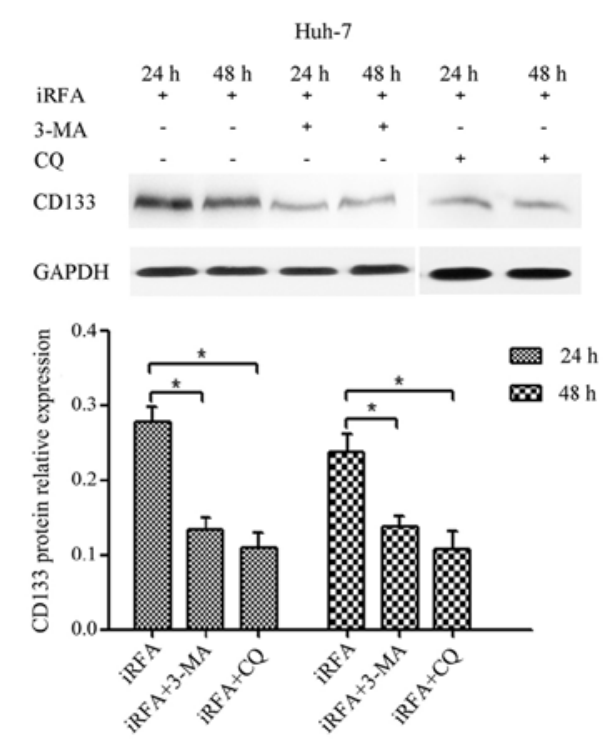

B

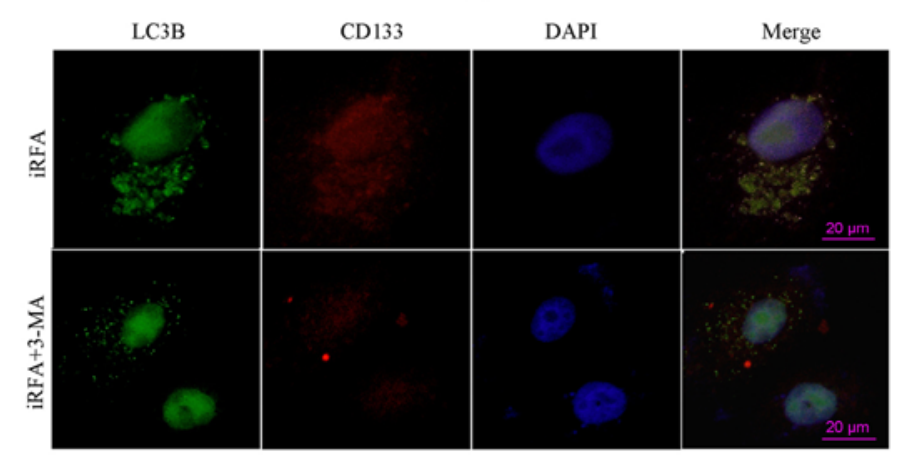

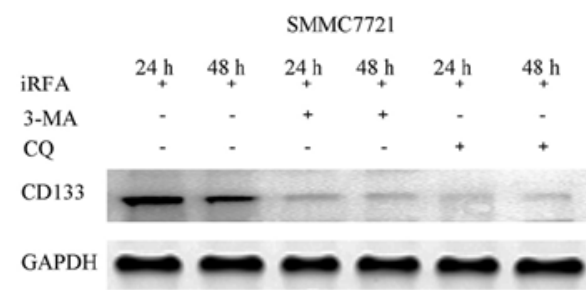

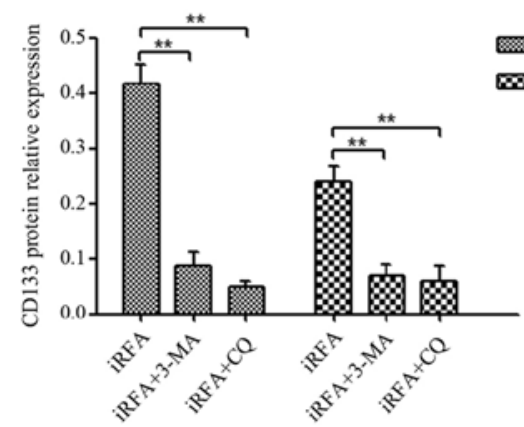

SMMC7721

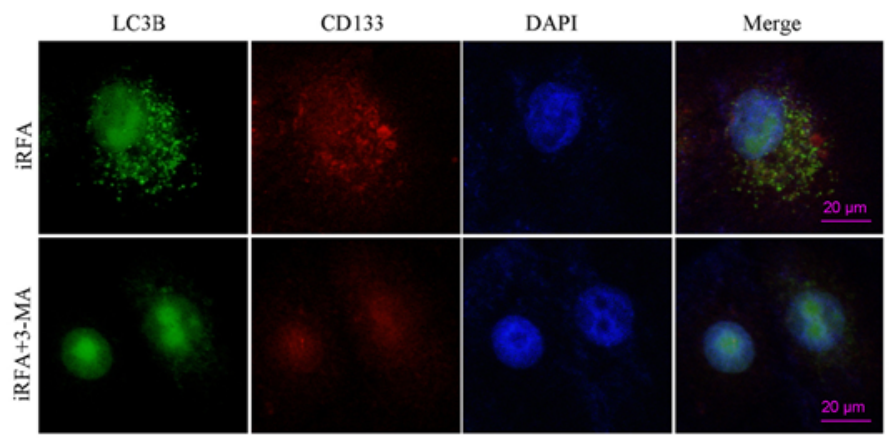

Figure 5. Inhibition of autophagy suppresses CD133 expression of HCC cells after iRFA treatment. (A) Huh-7 and SMMC7721 cells were exposed to iRFA treatment in the absence or presence of 3-MA $(5 \mathrm{mM})$ or $\mathrm{CQ}(5 \mu \mathrm{M})$, and cultured at $37^{\circ} \mathrm{C}$ for 24 and $48 \mathrm{~h}$. Then, CD133 protein expression was determined by western blotting. GAPDH was used as a loading control. (B) Huh-7 and SMMC7721 cells were exposed to iRFA treatment in the absence or presence of 3-MA $(5 \mathrm{mM})$, then cultured at $37^{\circ} \mathrm{C}$ for $24 \mathrm{~h}$, and subjected to confocal microscopy analysis. ${ }^{*} \mathrm{P}<0.05 ;{ }^{* *} \mathrm{P}<0.01$.

provide evidence that CD133 plays a role in the regulation of autophagy after iRFA treatment, we assessed the effect of CD133 knockdown on the expression of LC3B-II and p62 protein in iRFA-treated Huh-7 and SMMC7721 cells. As shown in Fig. 7A, LC3B-II protein expression determined using western blotting in iRFA-treated Huh-7 and SMMC7721 cells transfected with CD133-siRNA was decreased by 87.5 and $79.5 \%$ when compared with that in cells transfected with the negative control siRNA, respectively (Fig. 7A). However, the p62 protein in iRFA-treated Huh-7 and SMMC7721 cells after CD133 knockdown was increased by 2.47 - and 1.50 -fold when compared with that in cells transfected with the negative control siRNA, respectively (Fig. 7A). Furthermore, confocal microscopy results revealed that the formation of LC3B puncta in iRFA-treated Huh-7 and SMMC7721 cells after inhibition of the CD133 protein was decreased by 71.5 and $72.0 \%$ when compared with the control group, respectively (Fig. 7B).

\section{Discussion}

Radiofrequency ablation (RFA) is accepted as a safe and effective therapy for the early stages of primary HCC (25). However, iRFA treatment has been reported as a risk factor of local recurrence (4). Thus, it is urgently required to understand the mechanisms by which local recurrence is induced to improve prognosis of HCC patients.

Recently, autophagy was revealed to be important in maintaining cancer cell survival through conferring stress tolerance and limiting damages (26). For instance, sorafenibinduced autophagy acts as a chemoresistance mechanism in HCC (27). In the present study, we revealed that LC3B (a key autophagic marker) expression was significantly induced in the residual HCC cells after RFA treatment in vivo (Fig. 1). In addition, iRFA treatment leaded to autophagy, autophagosome formation and autophagic flux in Huh-7 and SMMC7721 cells in vitro (Fig. 2). Therefore, we concluded that autophagy may play an important role in promoting rapid and aggressive recurrence of HCC after iRFA treatment. To determine the effect of autophagy on iRFA-induced rapid and aggressive recurrence of HCC, we blocked autophagy using 3-MA in Huh-7 and SMMC7721 cells exposed to iRFA treatment. Our results revealed that the inhibition of autophagy by 3-MA suppressed iRFA treatment-induced cell viability and invasion of HCC cells (Fig. 3). Thus, these findings demonstrated that autophagy acted as an accomplice of survival, malignant progression of HCC cells under iRFA treatment . In contrast, numerous studies have revealed that autophagy also functioned as a tumour suppressor in HCC. Li et al (28) 


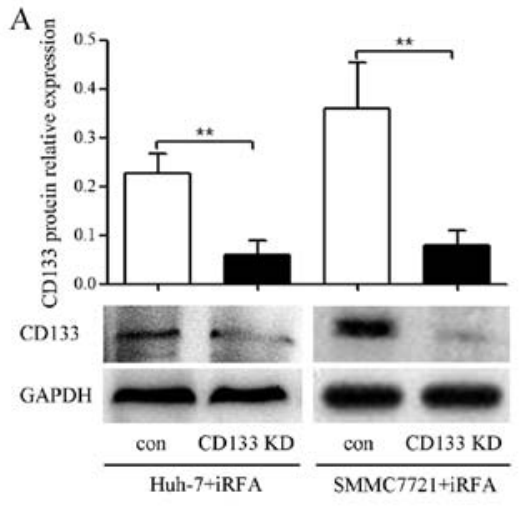

$\mathrm{C}$
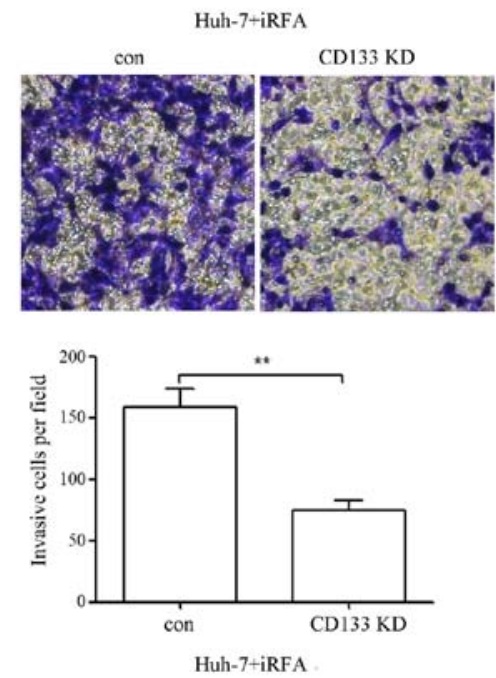

B
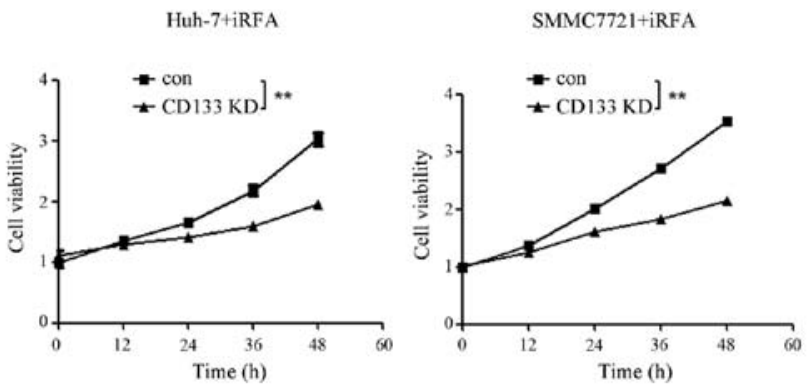

SMMC7721+iRFA
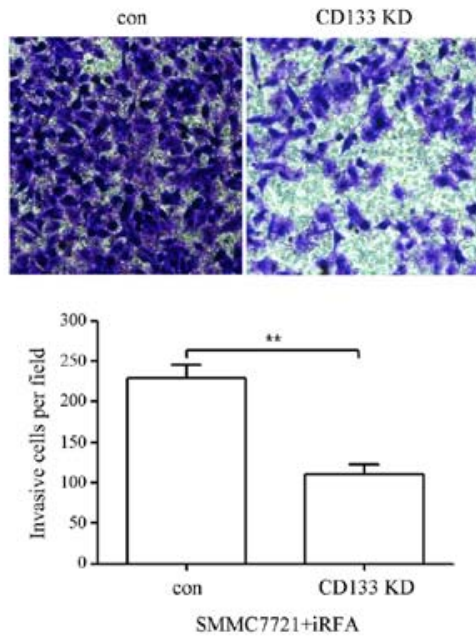

Figure 6. CD133 downregulation suppresses the enhanced cell viability and invasion of HCC cells after iRFA treatment. (A) The iRFA-treated Huh-7 and SMMC7721 cells were transfected with CD133-siRNA (CD133 KD) or negative control siRNA (con), and then CD133 protein expression was determined by western blotting. GAPDH was used as a loading control. (B and C) Cell viabilities and invasion abilities in iRFA-treated Huh-7 and SMMC7721 cells after CD133 knockdown were detected by CCK8 assay and Transwell cell-culture, respectively. Data are presented as the mean \pm SD $(\mathrm{n}=3)$. ${ }^{* *} \mathrm{P}<0.01$.

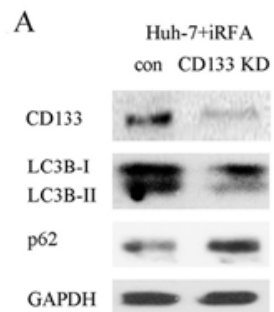

B
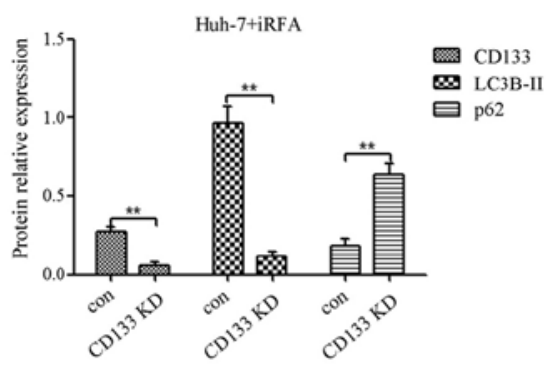
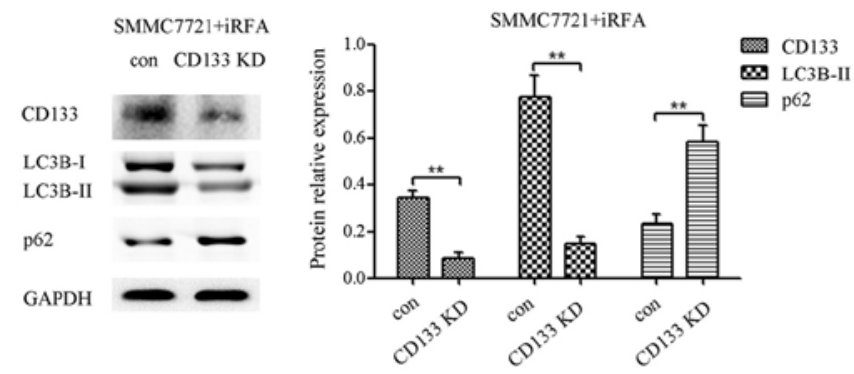

SMMC7721+iRFA

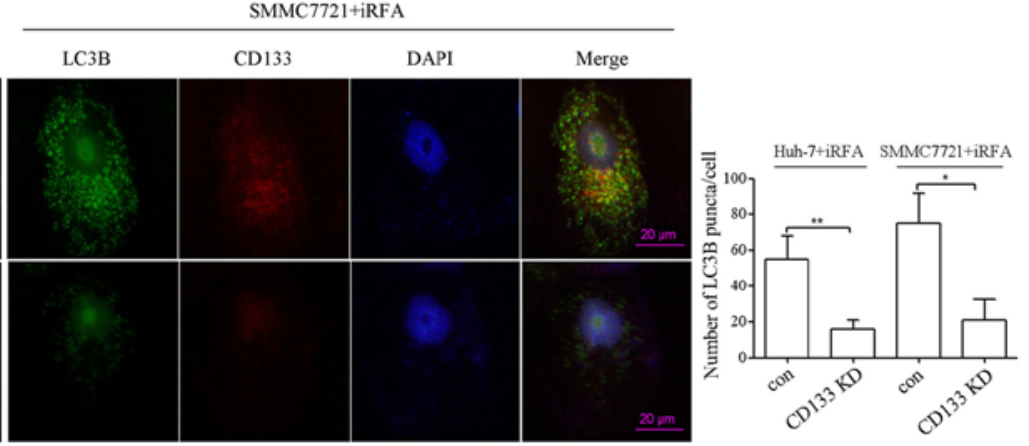

Figure 7. CD133 downregulation suppresses autophagy of HCC cells after iRFA treatment. (A) The iRFA-treated Huh-7 and SMMC7721 cells were transfected with CD133-siRNA (CD133 KD) or negative control siRNA (con), and then LC3B and p62 protein expression was determined by western blotting. GAPDH was used as a loading control. (B) Huh-7 and SMMC7721 cells transfected with CD133-siRNA (CD133 KD) or negative control siRNA (con) were exposed to iRFA treatment, then cultured at $37^{\circ} \mathrm{C}$ for $24 \mathrm{~h}$, and subjected to confocal microscopic analysis. ${ }^{*} \mathrm{P}<0.05 ;{ }^{* *} \mathrm{P}<0.01$. 
revealed that blocking of autophagy reversed the proliferation inhibition and cell death effects of IFN- $\gamma$ on HCC cells. In addition, Tay et al (29) revealed that lncRNA PTENP1induced autophagy may act as an inhibitory factor for HCC cell survival. These findings suggest that the role of autophagy in cancer is complex and is likely dependent on the microenvironment and genetic context.

Recent studies have demonstrated that high expression levels of putative hepatic stem/progenitor cell biomarkers such as CD133 confer enhanced malignant potential in HCC (30,31). In addition, iRFA treated-HCC cells displayed a higher CD133 expression and malignant potential (7). Moreover, Yang et al (22) found that blockade of autophagy by pharmacological or genetic inhibitors reduced CSC populations, sphere-forming ability, drug resistance and tumor formation in pancreatic cancer. In HCC, autophagy is essential for the survival and maintenance of $\mathrm{CD} 133^{+}$liver cancer stem cells (32). Thus, we proposed that induction of autophagy mediated by iRFA treatment contributes to aggressive recurrence of HCC via the promotion of progenitor characteristics. Further investigation supported this conclusion. First, we found that CD133 protein expression was significantly upregulated in vivo and in vitro and was positively correlated with LC3B protein expression in HCC specimens (Fig. 4B; $\mathrm{r}=0.636, \mathrm{P}<0.01)$. Second, CD133 protein colocalized with the autophagy protein LC3B in Huh-7 and SMMC7721 cells after iRFA treatment (Fig. 4D). Third, inhibition of autophagy by 3-MA or CQ significantly suppressed the expression of the CD133 protein in iRFA-treated Huh-7 and SMMC7721 cells (Fig. 5A and B). Fourth, CD133 knockdown by CD133-siRNA significantly suppressed cell viability and invasion ability in iRFA-treated Huh-7 and SMMC7721 cells (Fig. 6).

Notably, CD133 has been indicated to improve the resistance of glioma cells to a nutrient-deprived microenvironment by participating in autophagosome biogenesis (33). Meanwhile, Chen et al (24) found that CD133 is involved in cell survival through regulation of autophagy and glucose uptake in HCC. To further explore whether CD133 could regulate autophagosome biogenesis in iRFA-treated Huh-7 and SMMC7721 cells, we downregulated CD133 protein expression by CD133-siRNA. Our results indicated that CD133 downregulation significantly suppressed LC3B-II protein expression and autophagosome biogenesis, and induced p62 protein expression in iRFAtreated Huh-7 and SMMC7721 cells (Fig. 7). Thus, our results strongly indicated that iRFA treatment could also promote autophagy by inducing CD133 protein expression.

In conclusion, we identified a new mechanism by which iRFA promotes rapid growth and invasion of HCC cells by regulating autophagy and the CD133 feedback loop. These findings provide novel effective targets for the prevention and treatment of this undesirable effect during RFA therapy.

\section{Acknowledgements}

Not applicable.

\section{Funding}

The present study was supported by the Surface Project of the National Natural Science Foundation of the People's Republic of China (no. 81272688) and the Key Project of Application Development of Chongqing (no. cstc2014yykfB10002).

\section{Availability of data and materials}

All data generated in this study are included in this published article.

\section{Authors' contributions}

$\mathrm{KM}$ and $\mathrm{PB}$ designed this research. XW and QD performed the research. KF, SC, JJ and FX analysed the data. XW and FX edited the manuscript. All authors read and approved the manuscript and agree to be accountable for all aspects of the research in ensuring that the accuracy or integrity of any part of the work are appropriately investigated and resolved.

\section{Ethics approval and consent to participate}

In the present study, the use of human tissue samples and all experimental procedures and protocols were approved by the Ethics Committee of the First Affiliated Hospital of Third Military Medical University with the following reference no. 2013(47).

\section{Consent for publication}

Written informed consent was obtained from all of the patients prior to treatment.

\section{Competing interests}

The authors declare that they have no competing interests.

\section{References}

1. Forner A, Llovet JM and Bruix J: Hepatocellular carcinoma. Lancet 379: 1245-1255, 2012.

2. Kang TW, Lim HK and Cha DI: Aggressive tumor recurrence after radiofrequency ablation for hepatocellular carcinoma. Clin Mol Hepatol 23: 95-101, 2017.

3. Germani G, Pleguezuelo M, Gurusamy K, Meyer T, Isgrò G and Burroughs AK: Clinical outcomes of radiofrequency ablation, percutaneous alcohol and acetic acid injection for hepatocelullar carcinoma: A meta-analysis. J Hepatol 52: 380-388, 2010.

4. Lee HY, Rhim H, Lee MW, Kim YS, Choi D, Park MJ, Kim YK, Kim SH and Lim HK: Early diffuse recurrence of hepatocellular carcinoma after percutaneous radiofrequency ablation: Analysis of risk factors. Eur Radiol 23: 190-197, 2013.

5. Obara K, Matsumoto N, Okamoto M, Kobayashi M, Ikeda H, Takahashi H, Katakura Y, Matsunaga K, Ishii T, Okuse C, et al: Insufficient radiof requency ablation therapy may induce further malignant transformation of hepatocellular carcinoma. Hepatol Int 2: 116-123, 2008.

6. Ke S, Ding XM, Kong J, Gao J, Wang SH, Cheng Y and Sun WB: Low temperature of radiofrequency ablation at the target sites can facilitate rapid progression of residual hepatic VX2 carcinoma. J Transl Med 8: 73, 2010.

7. Yoshida S, Kornek M, Ikenaga N, Schmelzle M, Masuzaki R, Csizmadia E, Wu Y, Robson SC and Schuppan D: Sublethal heat treatment promotes epithelial-mesenchymal transition and enhances the malignant potential of hepatocellular carcinoma. Hepatology 58: 1667-1680, 2013.

8. Liu Z, Dai H, Jia G, Li Y, Liu X and Ren W: Insufficient radiofrequency ablation promotes human hepatoma SMMC7721 cell proliferation by stimulating vascular endothelial growth factor overexpression. Oncol Lett 9: 1893-1896, 2015.

9. Ma S: Biology and clinical implications of CD133(+) liver cancer stem cells. Exp Cell Res 319: 126-132, 2013. 
10. Tong CM, Ma S and Guan XY: Biology of hepatic cancer stem cells. J Gastroenterol Hepatol 26: 1229-1237, 2011.

11. Yang S, Wang X, Contino G, Liesa M, Sahin E, Ying H, Bause A, Li Y, Stommel JM, Dell'antonio G, et al: Pancreatic cancers require autophagy for tumor growth. Genes Dev 25: 717-729, 2011.

12. Wu DH, Jia CC, Chen J, Lin ZX, Ruan DY, Li X, Lin Q, Min-Dong, Ma XK, Wan XB, et al: Autophagic LC3B overexpression correlates with malignant progression and predicts a poor prognosis in hepatocellular carcinoma. Tumour Biol 35: 12225-12233, 2014.

13. Chang Y, Yan W, He X, Zhang L, Li C, Huang H, Nace G, Geller DA, Lin J and Tsung A: miR-375 inhibits autophagy and reduces viability of hepatocellular carcinoma cells under hypoxic conditions. Gastroenterology 143: 177-87.e8, 2012.

14. Peng WX, Xiong EM, Ge L, Wan YY, Zhang CL, Du FY, Xu M, Bhat RA, Jin J and Gong AH: Egr-1 promotes hypoxia-induced autophagy to enhance chemo-resistance of hepatocellular carcinoma cells. Exp Cell Res 340: 62-70, 2016.

15. Pinheiro C, Longatto-Filho A, Scapulatempo C, Ferreira L, Martins S, Pellerin L, Rodrigues M, Alves VA, Schmitt F and Baltazar F: Increased expression of monocarboxylate transporters 1, 2, and 4 in colorectal carcinomas. Virchows Arch 452: 139-146, 2008

16. Chen YJ, Chi CW, Su WC and Huang HL: Lapatinib induces autophagic cell death and inhibits growth of human hepatocellular carcinoma. Oncotarget 5: 4845-4854, 2014.

17. Kader M, Alaoui-El-Azher M, Vorhauer J, Kode BB, Wells JZ, Stolz D, Michalopoulos G, Wells A, Scott M and Ismail N MyD88-dependent inflammasome activation and autophagy inhibition contributes to Ehrlichia-induced liver injury and toxic shock. PLoS Pathog 13: e1006644, 2017.

18. Klionsky DJ, Cuervo AM and Seglen PO: Methods for monitoring autophagy from yeast to human. Autophagy 3: 181-206, 2007.

19. Fan T, Chen L, Huang Z, Wang W, Zhang B, Xu Y, Mao Z, Hu H and Geng $Q$ : Autophagy activation by rapamycin before hypoxiareoxygenation reduces endoplasmic reticulum stress in alveolar epithelial cells. Cell Physiol Biochem 41: 79-90, 2017.

20. Mizushima N: Methods for monitoring autophagy. Int J Biochem Cell Biol 36: 2491-2502, 2004.

21. Clevers H: The cancer stem cell: Premises, promises and challenges. Nat Med 17: 313-319, 2011.

22. Yang MC, Wang HC, Hou YC, Tung HL, Chiu TJ and Shan YS Blockade of autophagy reduces pancreatic cancer stem cell activity and potentiates the tumoricidal effect of gemcitabine. Mol Cancer 14: 179, 2015.

23. Mizrak D, Brittan M and Alison M: CD133: Molecule of the moment. J Pathol 214: 3-9, 2008
24. Chen H, Luo Z, Dong L, Tan Y, Yang J, Feng G, Wu M, Li Z and Wang H: CD133/prominin-1-mediated autophagy and glucose uptake beneficial for hepatoma cell survival. PLoS One 8: e56878, 2013

25. Bruix J and Sherman M; American Association for the Study of Liver Diseases: Management of hepatocellular carcinoma: An update. Hepatology 53: 1020-1022, 2011.

26. Van den Broeck A, Gremeaux L, Topal B and Vankelecom H: Human pancreatic adenocarcinoma contains a side population resistant to gemcitabine. BMC Cancer 12: 354, 2012.

27. Liu L, Liao JZ, He XX and Li PY: The role of autophagy in hepatocellular carcinoma: Friend or foe. Oncotarget 8: 57707-57722, 2017.

28. Li P, Du Q, Cao Z, Guo Z, Evankovich J, Yan W, Chang Y, Shao L, Stolz DB, Tsung A, et al: Interferon- $\gamma$ induces autophagy with growth inhibition and cell death in human hepatocellular carcinoma (HCC) cells through interferon-regulatory factor-1 (IRF-1). Cancer Lett 314: 213-222, 2012.

29. Tay Y, Kats L, Salmena L, Weiss D, Tan SM, Ala U, Karreth F, Poliseno L, Provero P, Di Cunto F, et al: Coding-independent regulation of the tumor suppressor PTEN by competing endogenous mRNAs. Cell 147: 344-357, 2011.

30. Kohga K, Tatsumi T, Takehara T, Tsunematsu H, Shimizu S, Yamamoto M, Sasakawa A, Miyagi T and Hayashi N: Expression of CD133 confers malignant potential by regulating metalloproteinases in human hepatocellular carcinoma. J Hepatol 52: 872-879, 2010.

31. Yang XR, Xu Y, Yu B, Zhou J, Qiu SJ, Shi GM, Zhang BH, Wu WZ, Shi YH, Wu B, et al: High expression levels of putative hepatic stem/progenitor cell biomarkers related to tumour angiogenesis and poor prognosis of hepatocellular carcinoma. Gut 59: 953-962, 2010.

32. Song YJ, Zhang SS, Guo XL, Sun K, Han ZP, Li R, Zhao QD, Deng WJ, Xie XQ, Zhang JW, et al: Autophagy contributes to the survival of $\mathrm{CD} 133^{+}$liver cancer stem cells in the hypoxic and nutrient-deprived tumor microenvironment. Cancer Lett 339: 70-81, 2013

33. Sun H, Zhang M, Cheng K, Li P, Han S, Li R, Su M, Zeng W, Liu J, Guo J, et al: Resistance of glioma cells to nutrient-deprived microenvironment can be enhanced by CD133-mediated autophagy. Oncotarget 7: 76238-76249, 2016.

This work is licensed under a Creative Commons Attribution-NonCommercial-NoDerivatives 4.0 International (CC BY-NC-ND 4.0) License. 